\title{
Laberintos textuales e intertextuales en E 1 cantor de tango de Tomás Eloy Martínez
}

\author{
Cecilia López Badano*
}

Resumen:

Este artículo propone que las claves de lectura de El cantor de tangos de Tomás Eloy Martínez se presentan como un complejo tejido de referencias intertextuales ofrecidas por las anécdotas y alusiones. La figura y metáfora del laberinto domina el texto en el nivel de su estructura, tópicos y referencias. La obra se configura así como la imbricación de varios laberintos textuales e intertextuales: uno urbano-arquitectónico, uno literario y otro de la memoria, explorados por la figura de un flaneur urbano. La idea de la novela es plantear un modo de contrahistoria, tal como la concibiera Walter Benjamin, y una reflexión sobre la violencia histórico-política. Al percibir estas claves de lectura, se concluye que la novela construye una memoria ficcional que busca reparar, con la recuperación de la microhistoria, la ausencia de los vencidos y avasallados por la historia oficial del siglo pasado en Argentina.

Palabras clave:

Tomás Eloy Martínez, novela argentina reciente, intertextualidad, microhistoria, contrahistoria, Walter Benjamin, flaneur, memoria colectiva, violencia histórico-política, anti-Estado, Jean Franco.

Antes de comenzar con el trabajo en sí, unas breves líneas argumentales sobre El cantor de tango, ya que es una novela relativamente

* Universidad Autónoma de Q uerétaro. 
reciente, en ella la anécdota es mínima: un narrador de mirada ajena -Bruno Cadogan, un estudiante norteamericano, sutilmente presentado como gay, que indaga para su tesis doctoral sobre los escritos de Borges sobre el tango- recorre la ciudad de Buenos Aires en busca de un cantor que le recomendara Jean Franco y que ofrece crípticos recitales. El peregrinaje de flaneur del narrador personaje diseña un mapa secreto, borgeano, asentado sobre las víctimas de crímenes impunes, las cuales irán recibiendo el homenaje sonoro del cantor a quien se persigue sin encontrarlo en el laberinto urbano.

El narrador eje del andamiaje ficcional constituye una alteridad cognitiva respecto del sujeto de la novelística previa tradicional (habitualmente un connacional, preferentemente, de sexo masculino) con relación a quien se presenta como "marginal". Esta elección permite consolidar una perspectiva que invalida, desde la visión externa, los estereotipos constitutivos de la nacionalidad y, por lo tanto, desacredita, en la visión de lo que los otros no ven, los principios de la identidad nacional.

La novela podría definirse como de "género anfibio", ya que su autor se resistiría a considerarla como novela histórica, pero si bien el momento principal de la narrativa se sitúa en el presente -la descomunal crisis argentina de fines del 2001-, está en permanente juego contrapuntístico con el pasado del último siglo que ingresa en forma de nouvelles abriendo la historia principal y construyéndola como otro enramado laberíntico entretejido y superpuesto a su vez sobre el laberinto ciudadano, arquitectónico.

Así, el eje ciudad-sociedad resulta una buena puerta de entrada al texto: en él se impone la presencia de la ciudad como escenario imprescindible de recuperación de la memoria; la percepción de la arquitectura urbana es perturbadora, desautomatizada cuando los volúmenes y sus texturas traen consigo mensajes de un ritmo profundo, escondido y doliente: el aleteo imperceptible de los condenados al silencio entre los "documentos de cultura" arquitectónicos de donde el curso de la historia ha borrado el rastro de su sangre.

Se pone así en juego lo que viera Halperín D onghi: 
Una experiencia que, como la vivida por Argentina [...] hace del terror una de las dimensiones básicas de la vida colectiva, redefine necesariamente el horizonte en que se desenvuelve la experiencia de cada argentino: su relación con su país, su ciudad, la calle en que vive no puede ser la misma después de que por años ha visto en ellos los lugares en que acecha la muerte. (71)

La clave del mensaje de los muertos -y de las muertes- es la recuperación de la memoria, de lo que se ha querido cubrir, de lo que emerge como fantasma; la ciudad y la memoria funcionan como espacios intercambiables, donde recorrer las calles de una es acceder a los laberintos de la otra. Como tan bien ha plasmado Piglia en uno de sus últimos relatos, también en este texto:

La ciudad trata entonces sobre réplica y representaciones, sobre la lectura y la percepción solitaria, sobre la presencia de lo que se ha perdido. En definitiva trata sobre el modo de hacer visible lo invisible y fijar las imágenes nítidas que ya no vemos pero que insisten todavía como fantasmas y viven entre nosotros. (Piglia 6)

El lugar urbano, geográfico, pero también memorístico y ficcional a un tiempo -convergencia de tres laberintos- ocupado por las víctimas indelebles de la violencia histórica, liga el "mapa geográficotextual" en una concepción humanista en la que convergen tres laberintos. D ice León Rozitchner: "Ciudad indiferente la ciudad teórica: por las historias se torna habitable. Hay que despertar los fantasmas que duermen en sus calles" (12). Así, los muertos que, distantes o cercanos en el tiempo, inquietan la arquitectura urbana de Buenos Aires fantasmagorizándola hacen que la novela se mueva dentro del ideario cuyo rumbo signaran previamente unas palabras de Marx en el 18 Brumario:

Los hombres hacen su propia historia, pero no la hacen a su libre arbitrio, bajo circunstancias elegidas por ellos mismos, 
sino bajo aquellas circunstancias con que se encuentran directamente, que existen y les han sido legadas por el pasado. La tradición de todas las generaciones muertas oprime como una pesadilla el cerebro de los vivos. Y cuando éstos aparentan dedicarse precisamente a transformarse y a transformar las cosas, a crear algo nunca visto, en estas épocas de crisis revolucionaria es precisamente cuando conjuran temerosos en su auxilio los espíritus del pasado, toman prestados sus nombres, sus consignas de guerra, su ropaje, para, con este ropaje de vejez venerable y este lenguaje prestado, representar la nueva escena de la historia universal. (9)

[...] En esas revoluciones, la resurrección de los muertos servía, pues, para glorificar las nuevas luchas y no para parodiar las antiguas, para exagerar en la fantasía la misión trazada y no para retroceder ante su cumplimiento en la realidad, para encontrar de nuevo el espíritu de la revolución y no para hacer vagar otra vez a su espectro. (11)

Sólo que en esta resurrección ficcional de los muertos, si bien hay una fuerte voluntad de toma de conciencia a través de la memoria, ya no hay voluntad de cambio que detenga la decadencia ni nueva lucha más allá de la veneración a través del obstinado recuerdo en combate con la historia oficial, puesto que se ha perdido la fe en encontrar una vez más el espíritu de revoluciones de las que sólo vagan los espectros.

De todos modos, como señala Michel De Certeau sobre el discurso histórico (62-63), ese discurso sobre el pasado en el que circula el muerto como objeto ausente tiene también en esta novela el sentido de la comunicación entre presentes. En la remisión al muerto como intercambio entre vivos, se juega, por una parte, el espacio simbólico de la "inmortalización", por la otra, el trabajo con la dimensión política de la memoria, que más que una restitución es inscripción de una falta de la que la comunidad debe ser consciente, como señala Rojas en su texto sobre la memoria: 
El trabajo con la dimensión política de la memoria no tiene entonces el sentido de una "restitución", si se entiende por tal simplemente la suplencia o compensación diferida de una "presencia", sino que se trata más bien de la inscripción, en el presente, del acontecimiento de la desaparición. Inscripción de la falta en el presente. (Rojas 182)

¿Qué sucede con aquellos muertos que pueblan el paisaje urbano? Una pregunta de Habermas, en su libro sobre las identidades nacionales y postnacionales, puede ponerse en contacto con la actitud y la respuesta que el narrador parece trazar en estos textos. Hablando del "después" de los campos de concentración, el filósofo nos dice:

Pero, tras aquella catástrofe moral, ¿no pesa sobre la supervivencia de todos nosotros, aunque de forma algo menos pronunciada, la maldición del simple habernos librado de aquello? ¿y no funda ese carácter fortuito del mero habernos librado de aquello una responsabilidad intersubjetiva, una responsabilidad en lo tocante a los plexos de vida distorsionados, que sólo garantizan la felicidad o incluso la simple existencia de los unos al precio de la aniquilación de la felicidad, de la negación de la vida, y del sufrimiento de los otros? (878)

En consecuencia, el personaje del cantor tratará, con su homenaje, de responder a esas preguntas evadiendo la maldición que pesa sobre la supervivencia "postraumática" y asumiendo, en la trama del relato, la responsabilidad intersubjetiva de reparar el olvido a través de la construcción de una memoria, al menos, ficcional - la que reconstruye el narrador, es decir, la propia novela- donde los datos recobrados se transforman, por ende, en homenaje literario, en letra que recupera la micro-historia o las pequeñas historias avasalladas que también construyeron país. Como señala Jean Franco:

Aunque las voces de los muertos denigrados o de aquellos que han desaparecido se supriman en el discurso oficial y hasta 
se borren del archivo histórico, ellas invaden la polis a través del mito y la leyenda y son evocadas por el paisaje, pues la historia y la memoria parecen discurrir por sendas diferentes, la primera preservada por medio de la documentación, los monumentos, las fiestas y conmemoraciones nacionales, la segunda mediante la tradición oral y la cultura popular. (162)

La novela, al hacer coincidir la arquitectura monumental con la tradición oral, con la leyenda urbana y/ o la cultura popular, con lo reprimido de la historia oficial y sus celebraciones, logra que historia y memoria - al menos, una memoria ficcional, homenajeantetransiten por la misma senda en una literatura que se enfrenta de modo cuestionante a la política; en consecuencia con este gesto unificador, se juega - como disputa contrapuntística con la historia oficial- la visión de la historización y, en su consideración, se impugna el paradigma historicista del progreso liberador.

Cuando se cuestiona el paradigma progreso mágicamente liberador, la posibilidad de narración triunfalista se quiebra, y la elección narrativa viene signada por la aproximación a la visión de Benjamin en las Tesis sobre la H istoria - ya veremos más adelante que la mención a Benjamin (referencia obligada también en el texto de Habermas mencionado) no es para nada arbitraria- por ello también la ciudad que se recorre como flaneur desorientado está en el centro: es en ella donde los "documentos (monumentos) de cultura" han encubierto los "documentos de barbarie" y la mirada es, como en las Tesis - o como la imagen del ángel- desde la cicatriz.

Entrando ya plenamente en la novela, puede decirse que una de las particularidades que vuelve sugestiva la narrativa de Tomás Eloy Martínez es su facilidad para ser leída en distintos niveles de profundidad: el lego puede aproximarse a ella por su prosa tersa y accesible, por su intriga, por el andamiaje casi policial de sus tramas; sin duda, se perderá sutilezas y exquisiteces, pero pasará un momento agradable sin poder desprenderse fácilmente de la lectura; en cambio, el letrado -y sobre todo, el intelectual versado en el canon literario argentino- además de esto, encontrará un sutil tejido de referencias intertextuales encargadas de transportarlo a un mundo 
metaficcional, que en este caso concreto, trasciende la factura del texto, pero que se teje como red a partir de él.

D e acuerdo con ello, una de las consideraciones iniciales que cabe hacer es sobre el título - siempre en Martínez una sutil instrucción de lectura- inspirado por The jazz singer, uno de los primeros films en utilizar el sistema sonoro Vitaphone, que sincronizaba la imagen con un disco fonográfico separado; Warners había utilizado el sistema para cortos, pero aquí añade cuatro secuencias sincronizadas a la película muda, con algunas escenas de diálogo que fascinaron al público, lo que produjo en breve la muerte del cine mudo y salvó a la Warners Brothers de la bancarrota; en el film, de 1927, dirigido por Alan Crosland, se consagra Al Jolson, hijo de inmigrantes ruso-judíos, llegado a Washington, aún niño, desde Lituania.

La cinta se menciona en el texto - también en El cantor de tango, los recitales fundamentales del moribundo cantor serán cuatro- $y$, además, se alude a Tango!, de 1933, uno de los primeros films sonoros argentinos (209-10). Se establece, por otra parte, una relación entre ambos a través de la primera frase "inmortal" de The jazz singer - "You ain't heard nothing yet"- (Bruno tampoco llegará a oír al cantor durante su búsqueda) y la primera frase "tormenta de significados" de Tango!: "Buenos Aires, cuando lejos me vi", frase de tango canónico ${ }^{1}$ que adquiere una importancia capital en el último capítulo, cuando se convierte en lo único que Bruno puede escuchar del moribundo cantor, y puede definir entonces su voz como "plena como una esfera", es decir - siguiendo otros paralelismos del relato- una voz-Aleph, que contiene la historia.

${ }^{1}$ Pertenece al tango L a canción de Buenos A ires, y su letra, de 1932, de Manuel Romero, dice: Buenos Aires cuando lejos me vi/ sólo hallaba consuelo/ en las notas de un tango dulzón/ que lloraba el bandoneón./ Buenos Aires, suspirando por ti/ bajo el sol de otro cielo,/ cuánto lloró mi corazón/ escuchando tu nostálgica canción./ / Canción maleva, canción de Buenos Aires,/ hay algo en tus entrañas que vive y que perdura./ Canción maleva, lamento de amargura,/ sonrisa de esperanza, sollo- 
Con esa figura para definir la voz se redunda sobre el parentesco de la novela con la estructura laberíntica "circular, en la que todo volvía al punto de partida" que el narrador le adjudica al film argentino (210), estructura circular, por otra parte, que, como se verá más adelante, es también la de Parque Chas, barrio -y laberintocentral en el relato, no sólo por ser la cuna del cantor, sino por ser aquél donde, como al guerrillero Andrade - su amigo y vecino- "la historia grande había rozado al Mocho con sus alas y él también oía el vuelo" (199). Ya veremos más adelante cómo se construye esta relación de laberintos superpuestos.

Para continuar, la pregunta inicial del trabajo interpretativo es ¿quién es ese escurridizo cantor de tango? Cualquier lector de la novela -aun los porteños más tangueros pero dedicados al tango "oficial" de las grabaciones- podría pensar que el personaje es ficticio, ya que está acuñado sobre una serie de rasgos que sintetiza los de varios cantores prototípicos de tango, como un ser, que es más o menos generalizado entre algunos de ellos el hecho de tratar de imitar la imagen, la postura, el peinado de Gardel.

Pero como siempre en el juego literario de Martínez, el dato, por citar un ejemplo, de la letra incomprensible en la canción hecha de palabras que no dicen, pero sugieren y condensan - adensan- significados, conjunta al menos dos referentes: el simbólico, de la futilidad de las palabras en el homenaje, de la innecesariedad de lo intelectual en la emoción, y el histórico: la biografía de Pascual Contursi, letrista fundacional del tango - con su letra de "Mi noche triste" el tango ingresó a los salones "respetables" en la voz de G ardel-, quien murió en un hospicio para enfermos mentales, en 1932, y cuyo extravío se inició, precisamente, con el síntoma de un hablar ininteligible.

zo de pasión./ Ese es el tango canción de Buenos Aires,/ nacido en el suburbio que hoy reina en el mundo./ Este es el tango que llevo muy profundo/ clavado en lo más hondo del criollo corazón./ / Buenos Aires donde el tango nació,/ tierra mía querida./Yo quisiera poderte ofrendar/ toda el alma en mi cantar/ y le pido a mi destino el favor/ de que al fin de mi vida/ oiga el llorar del bandoneón/ entonando tu nostálgica canción. 
Además de lo dicho, el nombre "real" - no el seudónimo artístico- elegido para el personaje -Estéfano Cacacce- suma también la referencia literaria, de laberinto intertextual, que se dimensiona en el final de la novela, en la muerte oscura y el velorio solitario del cantor: Stefano es quizás la obra teatral más relevante y conocida de Armando Discépolo dentro del género del que fuera magno exponente, es decir, el "grotesco criollo".

Allí se representa la historia de un inmigrante italiano, músico fracasado y en declive luego de que tanto él como sus padres vendieran cuanto tenían en Italia para intentar el sueño de ser compositor en América; por supuesto, como en la mayoría de las obras de ese género, el sueño se frustra cuando se ve obligado a trabajar en una modesta orquesta de Buenos Aires para ganarse el pan, y viven todos hacinados - también su mujer argentina y su hijo deficiente mental- en una miserable habitación de "conventillo"; el clímax se da en el momento en que su alumno llega allí a avisarle que, por sus reiterados errores ("pifiadas"), le quitarán el cargo y se lo han ofrecido a él.

El padre de Armando fue Enrique Santos, inmigrante italiano llegado a la Argentina antes de cumplir los veinte años, quien fuera el director de la primera Banda Municipal, lo que le permitía a Armando conocer profundamente ese ambiente y las mezquindades de músicos fracasados o mediocres en general; su hermano -Enrique Santos (h)- fue uno de los letristas más destacados del tango "canónico" - en particular, de los de más ácida filosofía, como "Uno", "Y ira yira" y "Cambalache".

Pero no, aún a pesar del simbolismo y la condensación ficcional, el cantor deforme y a la vez sublime - cuyo registro recuerda el timbre prodigioso del personaje de L a mano del amo, novela anterior que le sirve a Martínez como antecedente respecto del manejo literario del tema de la operística musicalidad de la voz- no es imaginario: su descripción está también inspirada en la figura - literariamente estetizada- de Luis Cardei, cantante casi secreto de recónditas cantinas porteñas primero; más tarde, de alguna librería y un club selecto. 
Casi no existen grabaciones de Cardei: grabó su primer disco compacto a mediados de los 90, lo que permitió que sus temas circularan algo más, y aun, su aparición en L a nube, el film de Pino Solanas estrenado en septiembre del 98. Murió en junio del 2000, a los 55 años, de una hepatitis contagiada en una de las transfusiones rutinarias a que lo sometía su cuerpo torturado por una hemofilia que lo había puesto varias veces al borde del abismo; además, había padecido poliomielitis de niño, enfermedades ambas descritas en el texto. Muchos de los que oyeron a este intérprete "real" en sus presentaciones nada comerciales lo han conceptuado como el mejor cantor de tango de los últimos tiempos. ¿Por quélo elige Martínez? Porque es el cantor anti-canon -ya que aun en lo popular del tango existe un canon fuerte-, de quien se ha dicho:

Era el mejor porque le había devuelto al tango su clásico formato de cuento intimista [...] Repasaba las letras como contando una historia conocida y pedía a lo sumo la complicidad emotiva de los que iban de su mano recorriendo el Buenos Aires irreal que sus versos traían y su vida reclamaba [...] con su repertorio desconocido, iluminó el camino por una geografía de añoranzas y emociones. Con esa voz de serenata, con su decir austero y delicado y con un fraseo que sabía donde estaba el énfasis y donde la piedad, desempolvaba viejas canciones y se burlaba dulcemente de los que trajinan con automatismo los temas de siempre [...] El repertorio de Cardei estaba hecho de aquellos tangos inocentes del $30 \mathrm{y}$ el cuarenta [...] "D espués del 40 -reflexionó en una entrevista- llegaron los poetas y los intelectuales y nos enseñaron que para sentir las letras hay que pensarlas. Y yo no quiero que mis tangos hagan pensar, yo necesito emocionarme con el argumento ya que juego interpretando al personaje". Por eso su repertorio bailotea sobre una ciudad y un tiempo que ya no están. (Castañeda)

Una vez desenmarañados los datos del exótico personaje, se puede pasar a decir que en $\mathrm{El}$ cantor de tango, justamente en el nivel 
que el letrado desentraña, se suman tres laberintos - el urbano, el de la memoria, el literario- de los cuales el más evidente es el primero, por su materialidad geográfica, acentuada por el recorrido "flaneurístico" del extranjero y por las menciones a los laberintos del libro de Prestel, tanta que, incluso, se vuelve arquitectónico en el barrio de Parque Chas - barrio extravagante teniendo en cuenta el trazado en perfecto damero de Buenos Aires-, donde transcurre uno de los capítulos relevantes: en él la historia se teje también como la calle circular, sin fin, de un laberinto, que es, a su vez, uno de los ejes de la política sangrienta de las décadas pasadas.

D ejándose vagar como flaneur, abandonándose en ese enjambre urbano, se accede, como revelación, al secreto del segundo laberinto, es decir, al secreto oculto de la memoria -el espacio que construye el cantor-. Cuando el cantor incrusta, con el encanto sutil de la voz y la canción, el denso espacio del pasado en la arquitectura vaciada del presente, su memoria condensa el tiempo -como dato conceptual- (el denso "antes" y el desmemoriado "ahora" aunados en el homenaje), en el espacio -como dato visual- (los "aquí" exóticos, desconocidos o naturalizados por la costumbre). "Sólo quisiera recordar lo que nunca he visto, dijo Martel aquella misma tarde. [...] Para Martel recordar equivalía a invocar, [...] a recuperar lo que el pasado ponía fuera de su alcance, tal como hacía con las letras de los tangos perdidos" (Martínez 68). Por todo ello, su voz, como hemos dicho, se definirá como "plena como una esfera", ya que, en la condensación de memoria que el canto evoca, se presentifica el Aleph, ese "punto en el espacio que contiene todos los puntos"; el canto de Martel es el Aleph que permite ver los lugares de la ciudad desde otros ángulos, y a través de esa definición metafórica, se superpone al laberinto de la memoria el laberinto literario del que hablaremos más adelante.

El pathos musical de los tangos señala y desenmaraña hechos que se convierten en epos literario dando visibilidad a otra historia a través del relato: mientras el cantor des(en)cubre un momento, un fragmento de temporalidad a través ya de la recuperación, en otro tiempo y en el mismo espacio, de personajes ignorados que flotan en un ayer detenido (Felícitas Alcántara, algunos guerrilleros, la 
prostituta polaca) ya de la reinterpretación de aquellos otros que fueron tratados heroicamente por una poco confiable historia oficial (Ramón Falcón), el narrador, en la desesperación por construir el epos -la verdad borrada, lo que el Estado esconde tras la arquitectura- trazará la relación cifrada entre política y literatura.

La letra de la canción, en sí, la mayoría de las veces no dice mucho, sólo indica, señala, sugiere la presencia de una historia acallada, sofocada y esa misma sugerencia condensa el tiempo en el espacio: "[...] Martel trataba de recuperar el pasado tal como había sido, sin las desfiguraciones de la memoria. Sabía que el pasado se mantiene intacto en alguna parte, en forma no de presente, sino de eternidad; lo que fue y sigue siendo aún será lo mismo mañana [...]" (Martínez 106). Cuando esa condensación - propia también de la característica mágica del Aleph- tiene lugar, surge lo propio del homenaje: "la desaparición de un cadáver peligroso da lugar a una evocación fantasmal; su presencia, por otro lado, invita a un ceremonial de despedida" dice Jean Franco. (163)

En el homenaje -siempre excéntrico a quien lo brinda y más excéntrico aún en este caso, cuando evita deliberadamente la enunciación de las loas- se centra la revelación mesiánica del cantor: "Yo canto sólo por eso: para que regrese lo que se fue y nada siga como está" (Martínez 199); el homenaje emerge de la magia de su canto como rito de pasaje que hace vibrar y "desconcierta" los andamios de la historia oficial, materializada en la arquitectura de los lugares. Esa fuerza que hace temblar las tuberías vacías con la vitalidad desconocida de la recuperación de la presencia pasada estallando en la planicie del presente es la de la contrahistoria -el vuelo de la historia "barrida a contrapelo", como quería Benjamin- que, aunque aún no dicha - aún no vuelta epos-, roza con sus alas y persiste en el recuerdo de alguien que no la dejará escapar.

En el canto, la historia se interpreta desde la fuerza mesiánica que domina a la memoria, por ello la mayoría de las veces - a excepción del tango "Volver", ${ }^{2}$ deliberadamente elegido por hablar de la

${ }^{2}$ Las estrofas finales dicen: Tengo miedo del encuentro/ con el pasado que vuelve/ a enfrentarse con mi vida.../ Tengo miedo de las noches/ que pobladas de 
memoria, "Margarita Gauthier" o "Sentencia"- no necesita una letra comprensible - no necesita enunciación-: como los contenidos de la memoria, nunca nos entrega la totalidad de su secreto y, en todo caso, vale por su pathos, no por su epos, ni por su logos racional -el epos, como ya hemos dicho, lo construye el narrador, es importante para él, que trata de desenmarañar lo oculto descubriendo una verdad, un mapa borrado, no para el cantor que, en todo caso, sostiene la coherencia de los puntos en el mapa y los hace decir.

El cantor quiere, como el ángel de la historia, ver una humilde redención - casi privada- brillar durante los segundos de libertad que regala su canto. Allí, como en la Crónica berlinesa de Benjamin "la memoria no es un instrumento para investigar el pasado, sino su espacio mismo"; surge así un tiempo que se "presentifica" mediante el homenaje para construir biografías urbanas a través de los recuerdos 0 , más bien, a través de la memoria negada tras la deliberadamente equívoca selectividad de historia oficial, el cantor señala desde el pathos lo que el narrador reconstruirá racionalizado en el epos.

Cuando el arte de perderse se convierte en estrategia textual -y de lectura-, en trasposición literaria de la experiencia de la urbe, se accede al tercer laberinto, es decir, al literario, ese espíritu en fuga de la ciudad de Buenos Aires, ciudad invisible -más permanente que la tan cambiante y fugitiva ciudad real- que es necesario reconstruir a través de los vaivenes de la estética del relato y funciona casi como un modelo ordenador. Como ha dicho Calvino: "Las ciudades invisibles son un sueño que nace del corazón de las ciudades invivibles" (15), pero aquí, a diferencia de las ciudades imaginarias de Calvino, donde la ciudad textual es proyección de la real, Bruno intenta construir a la inversa, con la modelización propia del extranjero culto, proyectando la ciudad real desde la ciudad textual, que entonces se "laberintifica".

recuerdos/ encadenan mi soñar.../ / Pero el viajero que huye,/ tarde o temprano detiene su andar.../ Y aunque el olvido, que todo destruye,/ haya matado mi vieja ilusión,/ guardo escondidauna esperanza humilde/ que es todalafortuna de mi corazón. 
Esta ciudad de letras, mirada como Aleph textual que duplica el mundo y como transpolado constructo intelectual de las lecturas de Bruno, ciudad que ahora, más allá del orden de los libros y las épocas, los géneros y los estilos, confronta cuando se le desordena en laberinto y logra redescubrir en otra dimensión, "material", podría decirse, es la propia "ciudad invisible", trazada sobre Benjamin, sobre Baudelaire, sobre Jean Franco, sobre J. G. Ballard, sobre el canon y el anticanon argentino, desde el fundante relato de $\mathrm{E} l$ matadero, de Esteban Echeverría, pasando por Roberto Arlt, Armando Discépolo, Borges, Sábato, Francisco Paco Urondo; sobre las mismas letras del tango que habían alimentado el imaginario intelectual de Bruno.

En la superposición de estos tres espacios, es decir, en la confrontación entre la materialidad de la arquitectura, los simbolismos de la construcción literaria que, también como imágenes urbanas consagradas en el exterior, "etiquetan" Buenos Aires, y la memoria que la tradición literaria modela negando otros espacios, surge otra ciudad: la que es -como el propio Aleph- imagen de la relación con el mundo, donde el laberinto es extensión no sólo espacial, sino también temporal, de la conciencia y de la historia, y donde el movimiento señalado - de la ciudad textual previa a la ciudad realvuelve a invertirse, para crear otra ciudad textual -la relatada- que sí sea, entonces, proyección de la real.

Cuando el extranjero puede ver con otros ojos, cada lugar se transforma en un espejo que refleja la imagen de toda una época y la nueva ciudad sofisticada y textual rebasa, desborda y convierte en extrañamiento las construcciones de las teorías poscoloniales que Bruno domina por haber sido formado intelectualmente en ellas, pero vuelve a ser orden en la escritura, es decir, orden textual: literatura. En esa ciudad textual que construye, Bruno, como el Benjamín de la crónica berlinesa, intenta indagar o descubrir acerca de "el género de gobierno que las ciudades imponen a nuestra imaginación" mientras traduce su desconcierto a lenguaje, a literatura.

Uno de los ejemplos paradigmáticos del entrelazamiento triádico de laberintos en el texto es la construcción literaria de Parque Chas que, en sus calles laberínticas, en sus casas iguales que no lo son, 
así como en los jardines delante de las casas donde jamás alguien pareciera detenerse, conjunta algunos de los elementos que concitaron el interés de Benjamín, y se vuelve entonces - como en Benjamin- uno de esos lugares donde los momentos del pasado anticipan el futuro.

Los desvíos del espacio que caracterizan al barrio (tanto al real como al literario) muestran -en el desconcierto del narrador caminante- que el laberinto se da también en el tiempo, como ha dicho el propio Martínez en el reportaje de Belvedere; cuando aparece la desorientación, la enredada disposición física del lugar se transforma en la enmarañada condición laberíntica del tiempo y se concentra en el espacio presente la suma temporal de los pasados, entonces, emerge de ello la propia historia nacional.

Este Parque Chas, políticamente, se vincula con otro motivo interesante: que justamente, el factor desencadenante del viaje de Bruno a Buenos Aires sea Jean Franco no es un detalle arbitrario, sino otro homenaje -éste, en vida y no póstumo-. En ese momento que ficcionaliza la novela, la brillante investigadora estaba escribiendo su maravilloso y documentadísimo D edine and Fall of the L ettered City. L atin A merica in the oold war, en uno de cuyos capítulos centrales - del que hemos tomado las citas anteriores- se discuten las representaciones literarias de los anti-Estados: precisamente, es uno de los hilos del anti-Estado el que se trenza en ese barrio, en la trama del secuestro del cadáver del general Aramburu para recuperar el cuerpo embalsamado de Eva Perón -ya entregado en ese entonces a Perón en Madrid luego de que los militares ordenaran su exhumación en un cementerio milanés donde había sido enterrada clandestinamente-. El operativo de secuestro del cuerpo del general golpista fue pensado por Paco Urondo cuyos versos aparecen en ese capítulo; Francisco "Paco" Urondo era intelectual y guerrillero montonero luego muerto en un enfrentamiento al inicio de la dictadura, aunque en realidad, tomó una píldora de cianuro antes de que lo capturaran vivo.

En el mencionado capítulo de su libro, Jean Franco, luego de recordar tanto Santa E vita, la novela de Martínez, como el Finnegan's Wake, dice: "La presencia del cadáver como estímulo para el re- 
cuerdo y la imaginación antes de que empiece el olvido adquiere un patetismo y un significado particulares cuando no se trata de un cadáver oficial. En ese caso, el velatorio restaura la importancia de ciertas vidas inimportantes y desviadas de la norma que han llegado a representar el anti-Estado" (163). Ésa será la sustancia del ritual del cantor: convocar las representaciones del anti-Estado (documentos de barbarie) para velar su presencia como la otra cara necesaria de los documentos (oficiales) "de cultura".

Desde el principio, además de Jean Franco ficcionalizada en el texto, marcando un rumbo interpretativo - el de los anti-Estados, 0 mejor, el de las representaciones físicas de los anti-Estados que construyeron la microhistoria ignorada muriendo a "contrapelo" de la historia-, dos citas a modo de epígrafe, que se relacionan también en el plano extratextual, funcionan como otra instrucción de lectura de E 1 cantor de tango: "... un eco repetido por mil laberintos" (Baudelaire, Las flores del mal), y: "El conocimiento llega sólo en golpes de relámpago. El texto es la sucesión larga de truenos que sigue" (Walter Benjamin, A rades Project). Luego, ya en el texto, se insiste:

Al pasar frente a la librería de la universidad recordé que quería comprar desde hacía mucho los diarios de viaje de Walter Benjamin. Los había leído en la biblioteca y me había quedado con las ganas de subrayarlos y escribir en los márgenes. ¿Qué podrían decirme sobre Buenos Aires esos apuntes remotos, que aluden a Moscú en 1926, a Berlín en 100? "Importa poco no saber orientarse en una ciudad": ésa era una frase que yo quería resaltar con tinta amarilla. (14)

Con ellas y en la alianza de los dos autores -Benjamín-Baudelaire- quedará cifrada la calidad de la mirada pendular sobre la ciudad que se construye en el relato, oscilando desde el polo irracional y desordenado que constituye la urbe del bien y el mal entremezclados con lo nuevo, lo decadente, lo cambiante en la obsesión de Baudelaire, a la fragmentaria lucidez intelectual racionalizadora de Benjamín, cuya mirada sobre la París de Baudelaire y sobre su propia Berlín es lo que la de Borges sobre Buenos Aires, ambos, 
brillantes lectores de los contrastes de la urbe moderna. A través de esa mirada, la ciudad pasa de ser constructo imaginario edificado sobre los textos "parecida a Kuala Lumpur: tropical y exótica, falsamente moderna, habitada por descendientes de europeos que se habían acostumbrado a la barbarie" (Martínez 14), a ser fuente material de una reflexión sobre la violencia histórico-política.

Evidentemente, la lectura - o relectura, mejor- de Benjamín marcó el rumbo de la escritura del texto. En 1999 había salido una reedición del A rcades project en inglés, la más completa hasta el momento - más de mil páginas-, basada en las notas originales del autor, aunque sin saber si el orden elegido hubiera sido el que Benjamín le habría dado al material. En uno de sus artículos para la prensa - "El próximo tren ya ha salido", para La N ación del 21 de enero del 2001- Martínez habla de la experiencia - un viaje en el tren rápido New York-Boston y alguna relación trabada en él- que lo condujo a la lectura de ese libro "cuyo lenguaje fragmentario, denso $\mathrm{y}$ a la vez urgente, tiene la intensidad de un testamento" y termina diciendo:

Casi toda la crítica norteamericana ha caído de rodillas ante esa obra monumental, parte de la cual estaba en las alforjas de Benjamin cuando se suicidó con una sobredosis de morfina, a comienzos de 1940, en la frontera entre Francia y España. Mi compañero leía en éxtasis, abrumando las páginas con anotaciones febriles, y no me animé a interrumpirlo. Pero apenas llegué a Boston compré The A rades Project en la librería de Harvard, donde lo venden por la décima parte de lo que vale.

Las páginas y la mirada de Benjamin estaban entonces frescas y recurrentes cuando el novelista inicia la escritura de El cantor de tango: el A rades Project es, además, el libro que Bruno compra en el último capítulo, cuando a su retorno comienza a ordenar y a escribir sus "memorias" de Buenos Aires; por ello, se diseñará la nueva ciudad ficcional no sólo como reseña de turista que se compromete más allá de lo previsto, sino como lugar de intersección entre la 
huella y el aura benjaminianas. Así, el cantor es el coleccionista de espacios, el que puede ver el aura del mundo pasado en la huella presente de la arquitectura que la encierra, o más bien, quien tiene el poder de descubrir el valor aurático de una arquitectura muda para los demás; el narrador será entonces quien vuelve palabra la huella que reivindica esa memoria mesiánica para transformarla en mensaje de reinserción de lo negado inscribiéndolo en el saber histórico, en la historia leída a contrapelo desde los mitos que establece la ficción.

Con el último homenaje del laberinto literario -a Juan G elman, escribiendo un verso suyo, sin nombrarlo, en las páginas finales ("callado como un niño bajo los gordos buitres")- y el retorno al laberinto histórico-político, en el último capítulo, en la breve referencia sintética y final a otros recitales previos del cantor - un homenaje al diputado Rodolfo O rtega Peña, primera víctima de la Alianza Anticomunista Argentina, salvajemente asesinado en pleno centro porteño-, se cierra la superposición de significados entramados sobre el propio laberinto urbano y el fino trabajo "esférico" de la novela como Aleph, que Martínez ha llevado a cabo y que, no por casualidad, tiene un final cíclico, en el que otro destacado profesor - Richard Foley- le menciona a Bruno un cantante mítico y críptico que ha descubierto en Buenos Aires. La esfera se completa y el Aleph sigue mostrando el pasado en la superposición de los caminos laberínticos de la memoria, la historiay la literatura que se vuelve política en la voz de juglares ignotos.

\section{Bibliografía}

Benjamin, Walter. Infancia en Berlín hacia 1900. Tr. Klaus Wagner. Madrid: Alfaguara, 1982.

Calvino, Italo. L as dudades invisibles. 1992. Tr. Aurora Bernárdez. Madrid: Siruela, 2000.

Castañeda, Alejandro. "Se fue Luis Cardei, un cantor de voz chiquita y sensibilidad enorme." E 1 día. La Plata: 24 de junio, 2000. 
De Certeau, Michel. L a E scritura de la H istoria. 1978. Tr. Jorge López Moctezuma. México: Universidad Iberoamericana, 1993.

Franco, Jean. D ecadencia y caída de la ciudad letrada. 2001. Tr. Héctor Silva Miguez. Barcelona: D ebate, 2003.

Habermas, Jürgen. "Conciencia Histórica e Identidad Postradicional." Identidades N acionales y Postnacionales. 1988. Tr. Manuel Jiménez Arredondo. México: Red Editorial Latinoamericana, 1993.

Halperín D onghi, Tulio. "El presente transforma el pasado: el impacto del reciente terror en la imagen de la historia argentina." Ficción y política. L a narrativa argentina durante el proceso militar. Buenos Aires: Alianza, 1987.

Marx, Karl. El dieciocho brumario de L uis Bonaparte. Moscú: Progreso, $\mathrm{s} / \mathrm{f}$.

Martínez, Tomás E. El cantor de tango. Buenos Aires: Planeta, 2004. . "El próximo tren ya ha salido." L a N ación. Buenos Aires, 21 de enero del 2001.

Piglia, Ricardo. "Prólogo." E l último L ector. Buenos Aires: AngramaEdigraf, 2005.

Rojas, Sergio. "Cuerpo, lenguaje y desaparición." Ed. Nelly Richard. Políticas y estéticas de la memoria. Santiago: Cuarto Propio, 2000. Rozitchner, León. Mi Buenos A ires querida. Buenos Aires: FCE, 2001. 